\title{
Innovative Devices for Daylighting and Natural Ventilation in Architecture
}

\author{
Oreste Boccia, Fabrizio Chella and Paolo Zazzini \\ D.S.S.A.R.R., University “G. D'Annunzio"Chieti, Pescara \\ Italy
}

\section{Introduction}

It is known that every human activity is better carried out in the presence of natural light than in the absence of it. This is probably due to the comfortable feeling of the occupants respect to the perception of the flowing of time, which is impossible when artificial lamps are the only light sources in the environment. In many cases the natural light is absent, as in underground areas of a building, or insufficient, as in the case of large plant area rooms, where the windows on the perimeter walls are not able to illuminate the whole environment being too small or too distant from the centre of the room. Moreover the indiscriminate use of electric light even if the daylight is available, due to a deplorable habit of the occupants of the workplaces, is a fairly common practice and it increases the energy consumption in buildings that already covers about $40 \%$ of the total energy consumed worldwide.

Many technological devices have been developed with the aim of contributing to an efficacy energy saving by using daylight in buildings, such the light pipes, that are able to transport the natural light away from the collection point, usually on the roof-top of the building, for example in hypogeum environments. There are two different types of light pipes depending on whether they are equipped with fixed or mobile collector. In recent years the authors carried out an intense experimental and numerical analysis with the aim to evaluate the daylight performances obtained by light pipes equipped with fixed collectors (Chella et al. 2006, Baroncini et al. 2006, Zazzini et al. 2006). Moving from the experience gained in the work, the authors developed some innovative devices which improve the performances of the traditional light pipes. The first one is called "Double Light Pipe" (DLP) and it is able to transport daylight into a two floors underground building. It is an evolution of the traditional light pipe. The second one is a further evolution of the DLP, which allows transport of daylight into underground areas of a building as a DLP, and guarantees the necessary change of air by natural ventilation. It is named "Ventilated Double Light Pipe" (VDLP) and it is simultaneously able to introduce daylight and fresh air in underground areas of buildings or rooms without direct interface with outdoor. This device was recently presented at the World Renewable Energy Congress 2011 (Boccia et al. 2011). Through a numerical analysis, the performances obtained by the VDLP and its applicability in architecture are examined. The numerical data allow the examination of the possibility of generating an architectonical space from the availability of daylight and fresh air by natural ventilation. 
The main goal of this work is to propose an architectonical space equipped with a certain number of VDLP, in which the geometry is generated by the availability of daylight and the possibility of effecting an efficacy of natural ventilation by the VDLP.

\section{Traditional light pipes}

The lack of daylight in buildings is often a cause of large amount of electric energy consumption. This problem is particularly present in the underground buildings or in industrial or commercial large plant area edifices in which electric light is used all the time in the spaces occupied. In recent years many technological devices, called light pipes, sky lights or tubular sky lights, have been proposed in order to offer a solution to the problem. They are able to collect natural light with a mobile or fixed collector and redirect it into the interior spaces away from the collection point.

Light pipes with mobile collectors can be equipped by heliostats that are solar tracking devices able to rotate with respect to one or two axis, so optimizing the direct solar radiation inlet into the tube.

Fixed collectors are cheaper than mobile collectors. They are usually constituted by a transparent polycarbonate dome with the function of collecting natural light from the sun and the sky and redirect it into the tube. In many cases they also have Fresnel lenses able to concentrate direct solar radiations coming from various directions in the direction parallel to the pipe.

The entrance point is in most cases located on the roof-top of the building or alternatively on one of the external walls. A free collection of light is needed for optimizing the efficiency of the device so that any obstruction of solar radiations from adjacent structures may be avoided.

The tube is internally covered by a highly reflecting film along its length from the collector to the diffuser for long-distance transport of natural light in the underground areas or spaces without any direct interface to outdoor. The larger the diameter of the collector, the longer the distance that can be covered by light with minimum dissipation of energy.

Light pipes on the market have diameters of the collector varying between 0,25 to $1 \mathrm{~m}$. The bigger light pipes are usually adopted in commercial or industrial applications. The smaller ones are used for residential installations and they are typically 1-5 $\mathrm{m}$ long.

Natural light is more efficiently transported with straight pipes, but curved or angled tubes can be adopted if necessary. Light transmission losses are reduced by the highly reflecting film applied on the internal surface of the tube. Reflectivity ranges from 0,98 to 0,995 .

In recent years many authors carried out numerical and experimental analysis with the aim to determine the performances of light pipes (Carter 2002, Zhang et al. 2002, Jenkins et al. 2003) and theoretical or empirical calculation methods were set up by various researchers for the prediction of the illuminance distribution inside a room equipped by light pipes (Jenkis \& Muneer 2004, Jenkis \& Zhang 2004), but standard design methods have not yet been developed. The difficulty in standardizing the calculation methods is mainly connected with the influence on internal illuminance distribution of the temporary weather variations that commonly occur during a day, a season or a year, and it is very difficult to describe the 
real climatic situation with a simplified model based on standard conditions that are necessary for a correct design of the system.

And finally in a room of a building equipped by light pipes, a polycarbonate light diffuser is applied to the ceiling in order to spread light into the room.

The authors published in Baroncini et al. (2006) the results of an experimental comparison between two types of commercial diffusers installed on the same light pipe for residential applications, and demonstrated that the geometry adopted in the diffuser can be modified for spatial distribution of light.

If compared to traditional skylights, the light pipes offer better performances in term of summer heat gain reduction, due to a less visual contact with outside. In addition the availability of natural light in hypogeal environments improves the occupants' well-being, avoiding over illumination effects. A significant energy saving contribution is offered by light pipes installations, by reducing the electric energy consumption.

Light pipes are often characterized by considerable dimensions, their installation in the centre of a passage room is unacceptable, being very bulky systems. When a light pipe is installed to transport natural light from the rooftop of the building to an underground room, the passage spaces are occupied by a very voluminous system which constitutes an undesirable stumbling block and makes it inconvenient to install it in the centre of the room.

\section{The Double Light Pipe}

The Double Light Pipe (DLP) is an innovative device developed by the authors to illuminate a two - level underground room. It is an improvement of the traditional light pipe, moving from the idea that the installation of a traditional light pipe in the centre of a two - floor building, with the aim of illuminating the lower underground spaces, is impossible because of the encumbrance of the device.

Since the DLP is able to distribute daylight both in to the passage and the final room, it is proposed to be a solution for the problem. In fact, if a double light pipe is used instead of a traditional one, it is in good agreement with the architectural principle because it illuminates the passage room, so justifying its bulkiness.

The DLP is an improvement on the traditional light pipe. It consists of two concentric tubes, the internal one which illuminates the final room like the traditional light pipe. The same reflective film ( $\rho=99,5 \%$ ) covers both the internal and the external surfaces of the inner pipe while the second one, concentric to the first, is made of a transparent material such as polycarbonate and it is installed so as to create a hole between the two pipes. It allows transmission of a portion of daylight, captured by the collector on the rooftop, into the interior spaces crossed by the system.

In figure 1 a picture is shown of a reduced scale (1:2) prototype of the DLP set up by the authors in the laboratory of Technical Physics of the University "G. D'Annunzio" of Pescara and the concept on which the device is based.

In order to diffuse light in the passage room, avoiding too intense reflections from the interior pipe, a thin plastic diffusing film is applied on the interior surface of the transparent external pipe. It is characterized by very precise $90^{\circ}$ micro-prisms on one side and is made 
smooth on the other so that it may distribute light in a more diffuse way in the crossed room.

Thanks to its optical properties, it can either reflect or transmit, depending on the angle of incidence of the light. radiation. Light is reflected if the angle is less than about $27^{\circ}$ with respect to the axis of the prisms, and transmitted if the angle is greater than $27^{\circ}$.

The diffusing film may be applied on the upper portion of the pipe $(30-50 \mathrm{~cm})$ in order to avoid glare. Figure 2 shows the construction steps of the system and its illuminating function in the passage and final room.
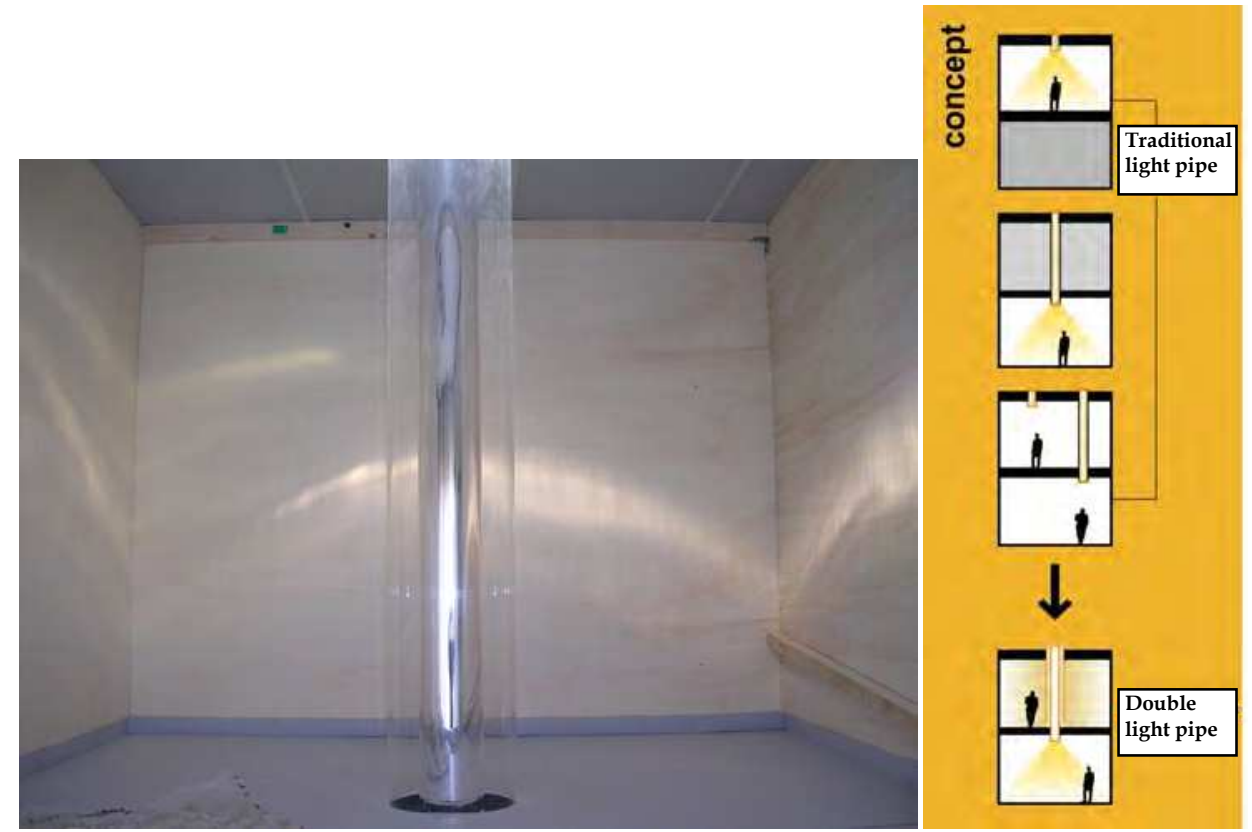

Fig. 1. Reduced scale prototype of a DLP and the concept of the system
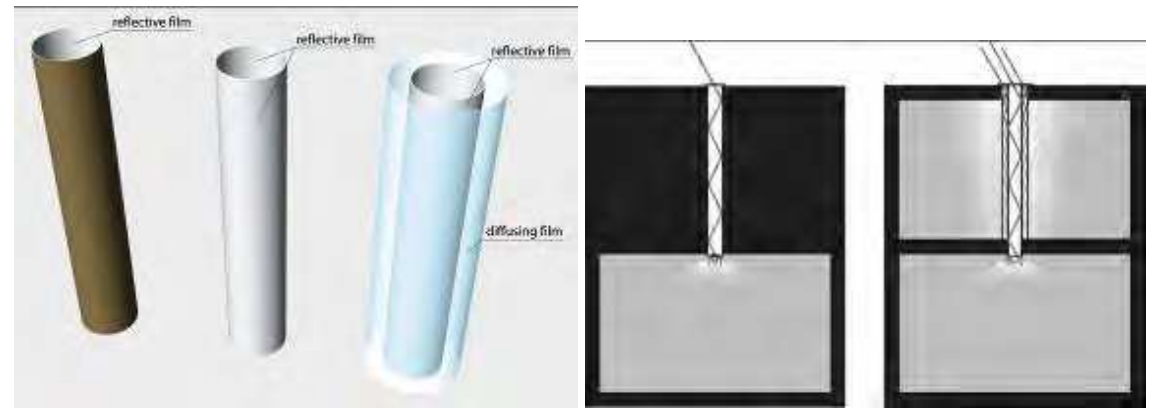

Fig. 2. Evolution from a traditional light pipe to a double light pipe and its lighting function in a two floor underground room 
Since the DLP provides light in the room, it can be installed in the centre of the area. The technological design of the DLP and data about its performances are shown in Chella et al. (2007), Baroncini et al. (2008), Baroncini et al. (2009), Baroncini et al. (2010).

The DLP can be installed either in underground rooms or large plant area spaces in which the windows are placed on the perimeter walls and they are not able to guarantee an efficient distribution of natural light in the whole environment. In such cases, the DLP is very suitable, particularly if a soft light distribution is required, characterized by a certain degree of uniformity, such as in exhibition rooms, museums and the like, in which direct solar radiations must be avoided because of the risk of glare and deterioration of the artworks sensitive to light. For this reason, in museums or other similar places, even if not in hypogeal rooms, any direct visual contact with outdoor is usually avoided and artificial light is used all the time in such environment.

The collector of a DLP is larger than a traditional one. It is able to collect light and redirect it both to the inner pipe and to the hole between the two pipes. It can be a dome or plane cover made of transparent material such as polycarbonate, equipped by Fresnel lenses or not.

In the reduced scale prototype set up by the authors, the simplest type of collector was adopted, a plane transparent polycarbonate device placed on the rooftop, with the intention of evaluating the performances of the transmitting and diffusing devices in the least favourable conditions. Any enhancement of shape and materials, with the aim of optimizing the possibility of collecting daylight, will obviously increase the performances of the DLP.

The inner pipe consists of an aluminium sheet folded like a tube which is covered by a multilayer highly reflective film both over its internal and external surfaces. Due to its reflecting characteristics, very efficient multiple reflections take place in the pipe; direct and diffuse natural light are channelled downward to the diffusion point in the final room.

The outer pipe, concentric to the inner one, is made of a transparent polycarbonate tube, internally covered partially or completely on its surface by a diffusing material, which distributes light into the passage spaces.

At the end point of the light path, in the final room, a conventional polycarbonate diffuser with a regular prismatic geometry was adopted similar to the traditional light pipe. In all respects the inner pipe performs like a traditional light pipe.

Figure 3 shows a two-dimensional section of a two - level underground building equipped by a DLP, in which the used materials are evident, while in Figure 4 an example of application of a DLP to an underground museum is shown. [Chella et al. 2007]

\subsection{Experimental analysis on the Double Light Pipe}

The authors carried out an intensive experimental and numerical analysis on the DLP. The experimental analysis was carried out on reduced scale models of the system, while for the numerical analysis, Radiance and Ecotect were used, two reliable soft-wares commonly used for daylight simulations (Chella et al. 2007, Baroncini et al. 2008, Baroncini et al. 2009, Baroncini et al. 2010) . 


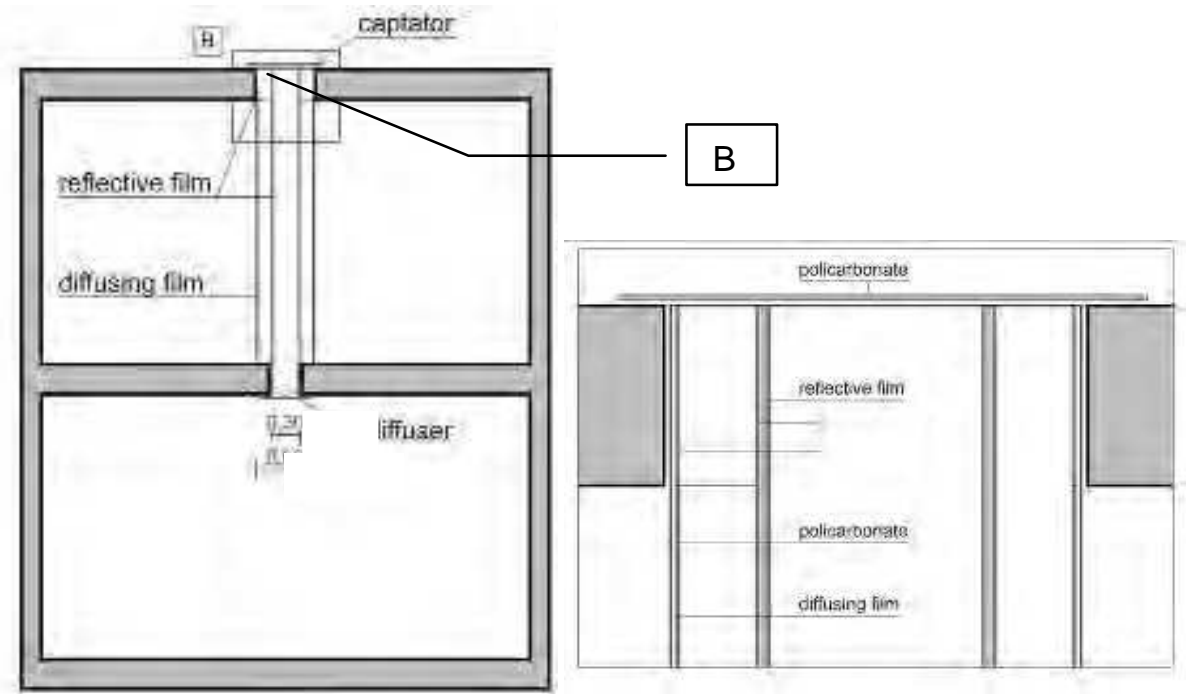

Fig. 3. Two dimensional section of a two levels building equipped by a DLP

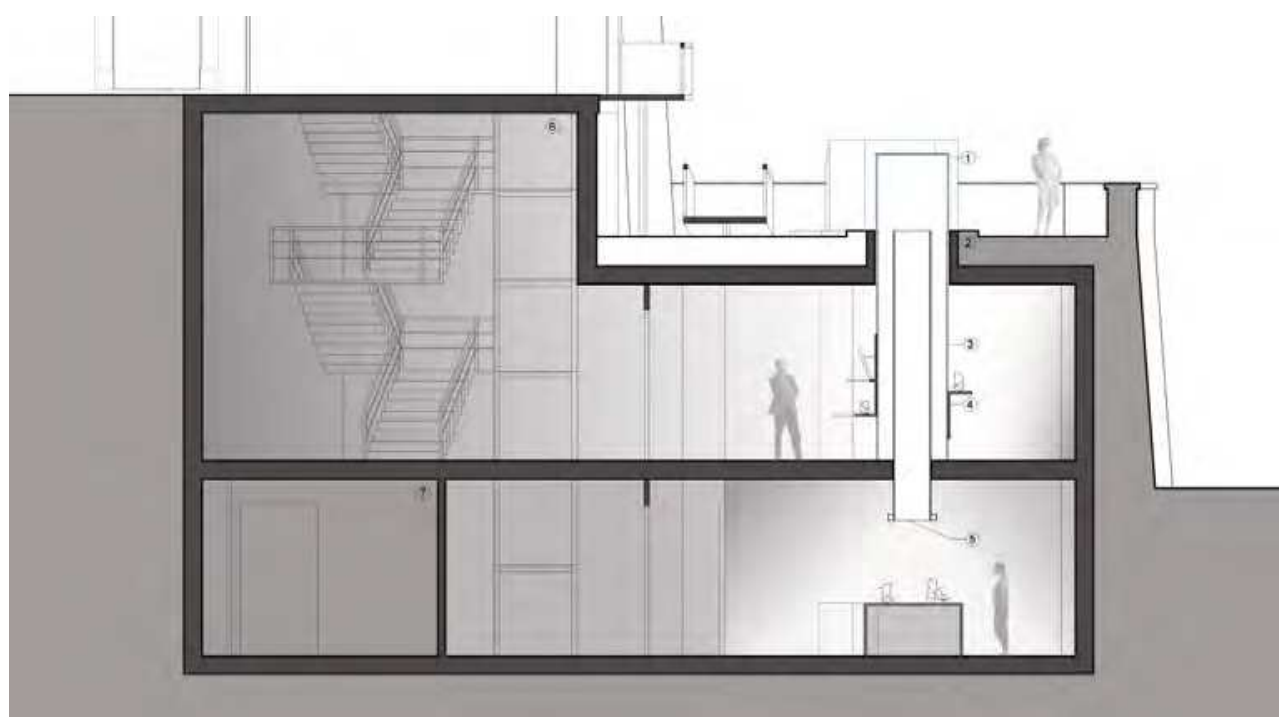

Fig. 4. Application of Double light pipes in a two levels underground museum.

The experimental data measured on a 1:2 scale DLP in three different tests are shown in the following figures. The results report the illuminance distribution in the passage area measured in 12 internal positions on a horizontal work-plane $40 \mathrm{~cm}$ high above the floor and outside of the building close to the collector on the roof-top as well are presented in the following figure. 


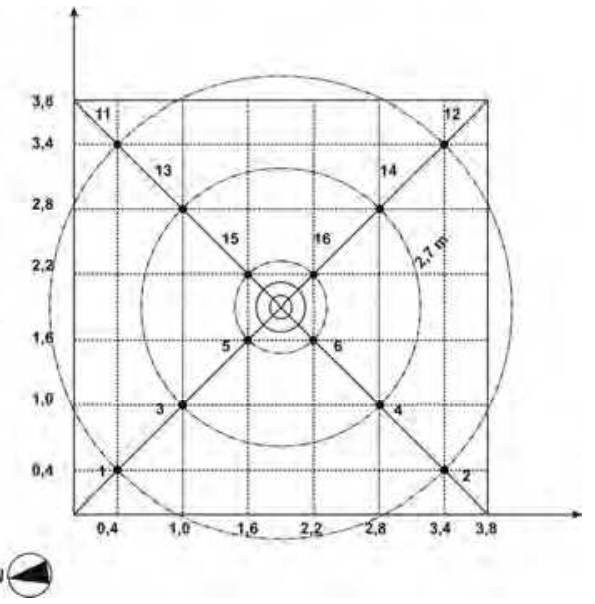

Fig. 5. Measure positions in the experimental tests on the 1:2 scale model of the DLP

Figure 6 shows the results of a test carried out under intermediate cloudy sky between 9 am and $1 \mathrm{pm}$. The external illuminance ranged between 17 and $76 \mathrm{klux}$, with a mean value of about 40 klux. It is evident that the interior illuminance trend is very similar to the external one in every position in the absence of direct solar radiation. Some peak values of illuminance observed in positions 1 and 2 close to the corners of the room at about 11 am may probably due to particularly intense reflections from the device. The ratio between $E_{\text {in }}$ and $E_{\text {ext }}$ is less than $1 \%$ all over the work-plane.

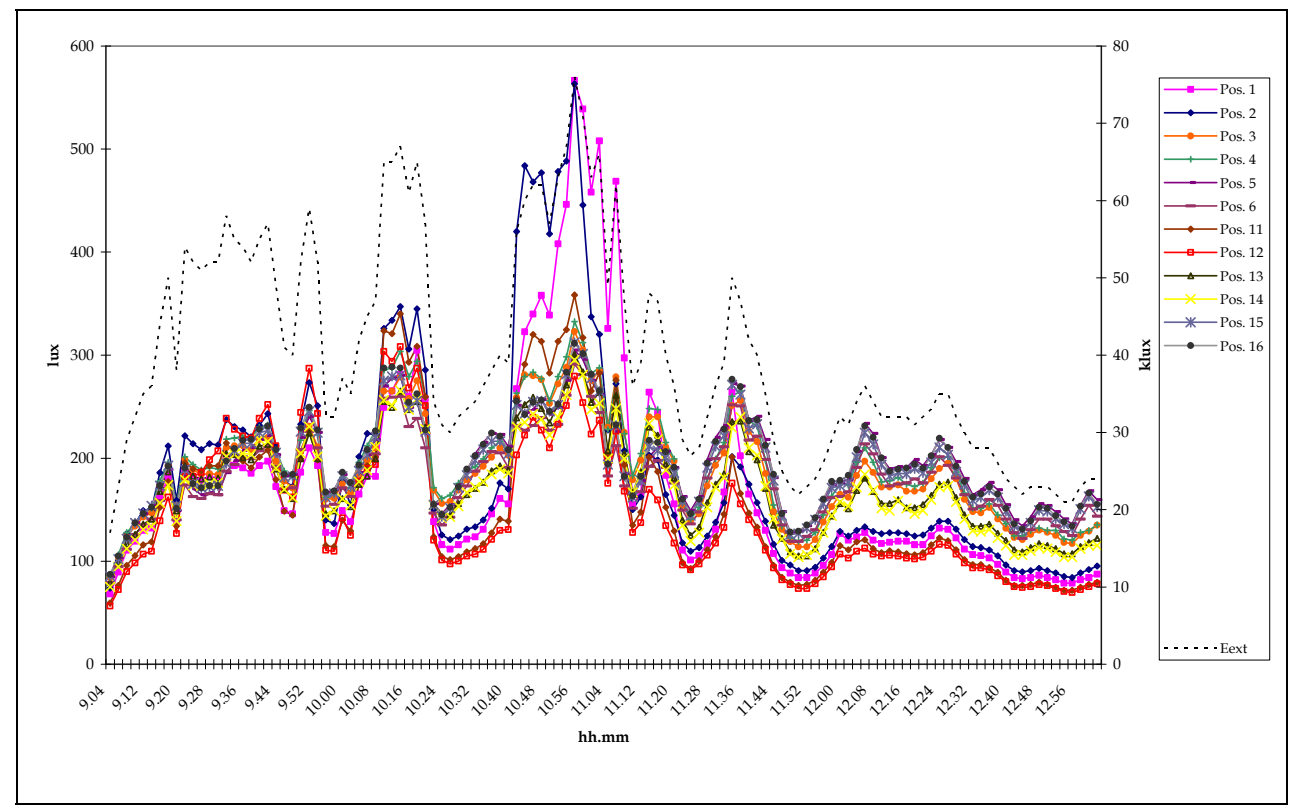

Fig. 6. Experimental data on a 1:2 scale model of a DLP under cloudy sky 
In Figure 7 data are shown regarding an experimental test effected on the same 1:2 scale model of the DLP with intermediate sky with sun, between 9 am and $4 \mathrm{pm}$, the external illuminance ranging between 18 and 73 klux with a mean value of about 56 klux. In this case, the peaks on the corner of the room are more evident than in the previous test, not only in positions 1 and 2, but also in positions 11 and 12 on the opposite side of the room, probably due to a more significant influence of direct solar radiations. Peaks of illuminance take place at points determined by the hourly positions of the sun in the sky and by the directions of high reflections generated by the system.

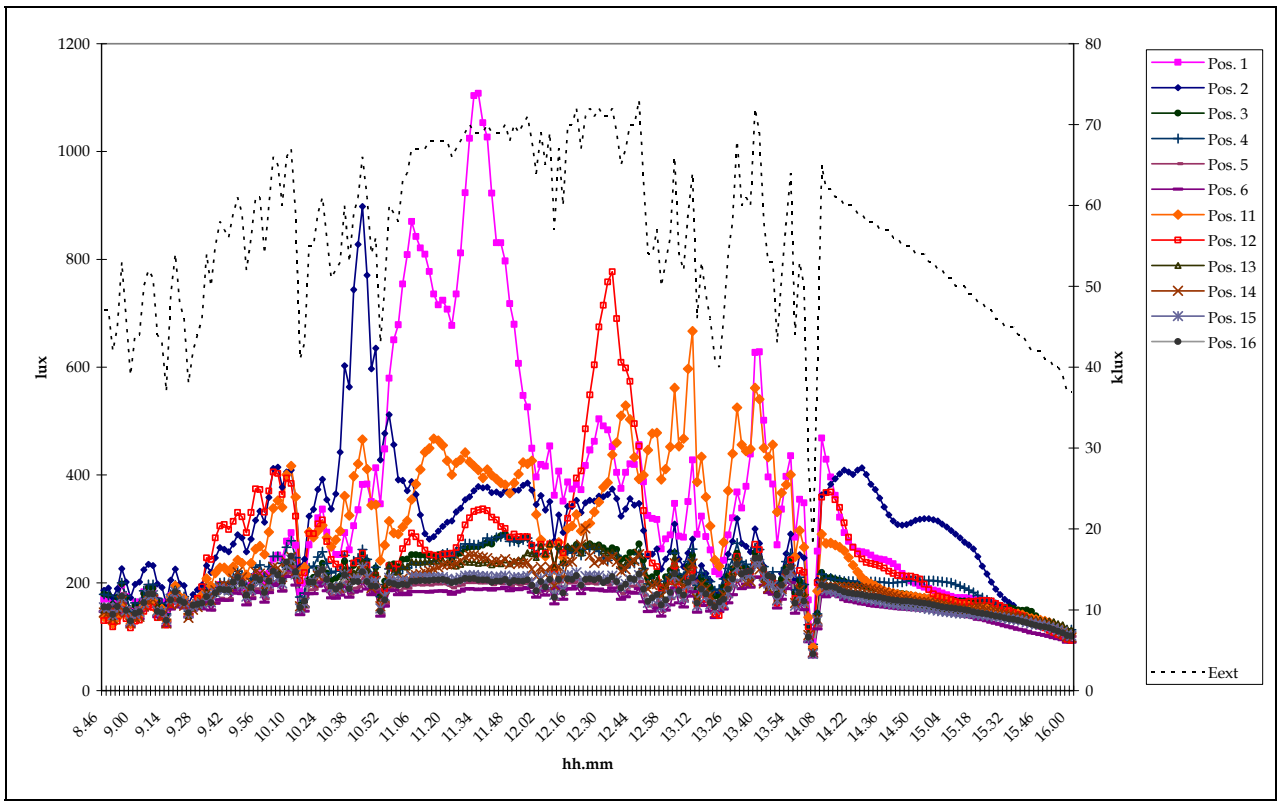

Fig. 7. Experimental data on a 1:2 scale model of a DLP under intermediate sky with sun

Finally, in Figure 8, the results of a two - day test on the same reduced scale model under clear sky with sun are shown. The test was carried out between 9 am of the first day and 3 $\mathrm{pm}$ of the second day. Corresponding to a more regular trend of the external illuminance, which is characterized by more powerful direct solar radiations (Eext ranges from 11 to 74 klux, with mean value of about 51 klux in the first day and from 11 to 72 klux with a mean value of 55 klux in the second day) the internal illuminance is characterized by very frequent illuminance peaks in various positions. The greater the external illuminance the more frequent the presence of the peaks.

Starting from this consideration, it is likely that high reflections from the DLP involve glare phenomena for the occupants of the environment. In such cases the use of the diffusing film described above can be an effective antidote to this possibility. 


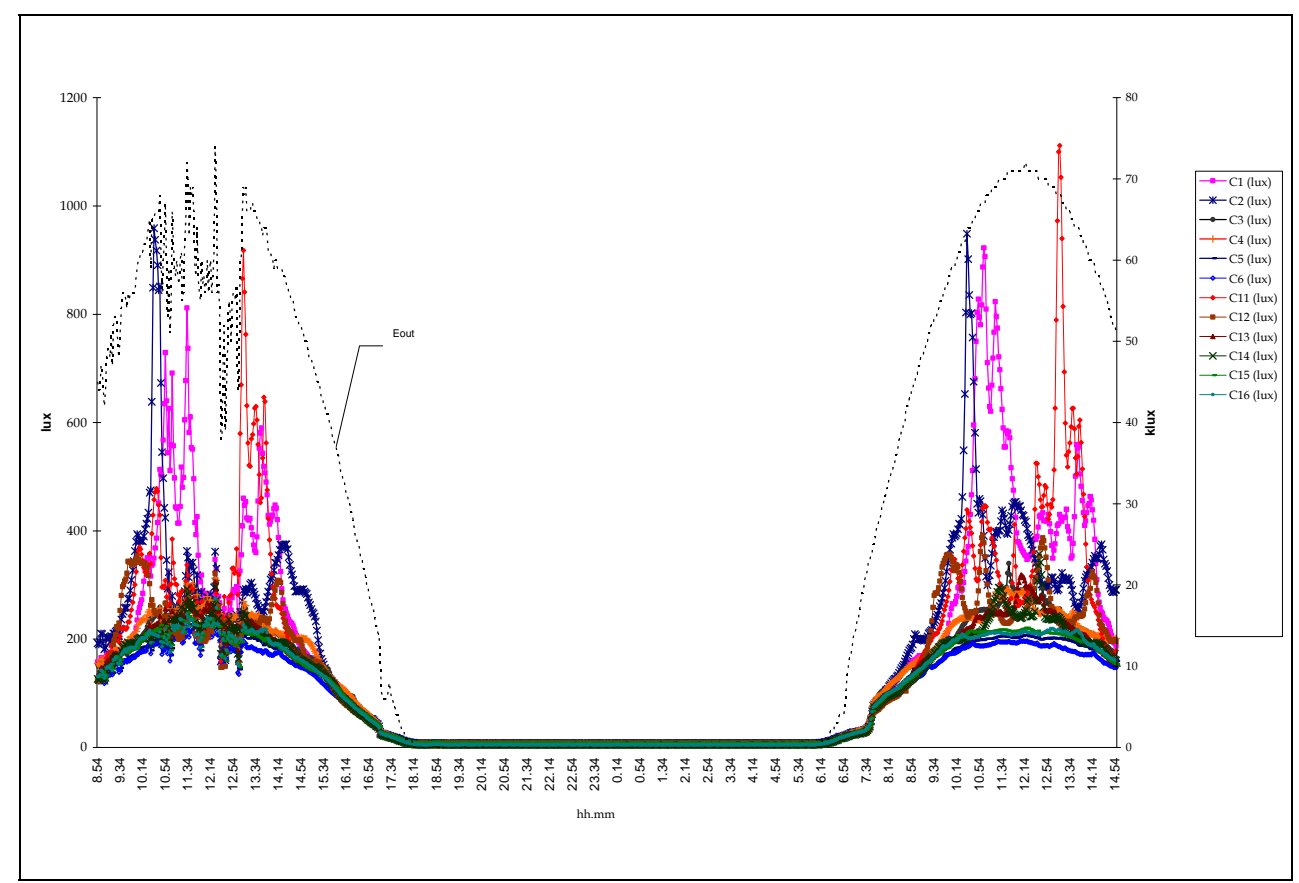

Fig. 8. Experimental data of a two - day test on a 1:2 scale model of a DLP under clear sky with sun

\section{The Ventilated Double Light Pipe}

People living or working in underground environments of buildings need both natural light and ventilation for well being. When air is made to flow by mechanical ventilation a considerable amount of electric energy has been consumed. Light pipes are often equipped by mechanical ventilation devices in order to assure comfortable optical and hygienic conditions for the occupants. For this need, the authors propose a modification of the DLP so that it can be used as an efficient tool for natural ventilation in the passage area in a twolevel underground building, allowing a significant energy saving. This device is named Ventilated Double Light Pipe (VDLP).

The Ventilated Double Light Pipe (VDLP) is a further transformation of the DLP which geometry is modified to optimize the air coming in and out. To be more precise, in the VDLP, the inner tube is narrowed at the top, in order to generate a convergent section at the top to improve the air extraction, while the outer tube is narrowed at the bottom, so the hole between the two tubes has a convergent section downward for the air to come in. In this way each device can be alternatively used as an inlet or an outlet system. Particularly, in the inlet VDLP the inner pipe is closed at the top and the bottom, while at the outlet the air cavity between the two pipes is closed at the top and bottom, as shown in Figure 9. 

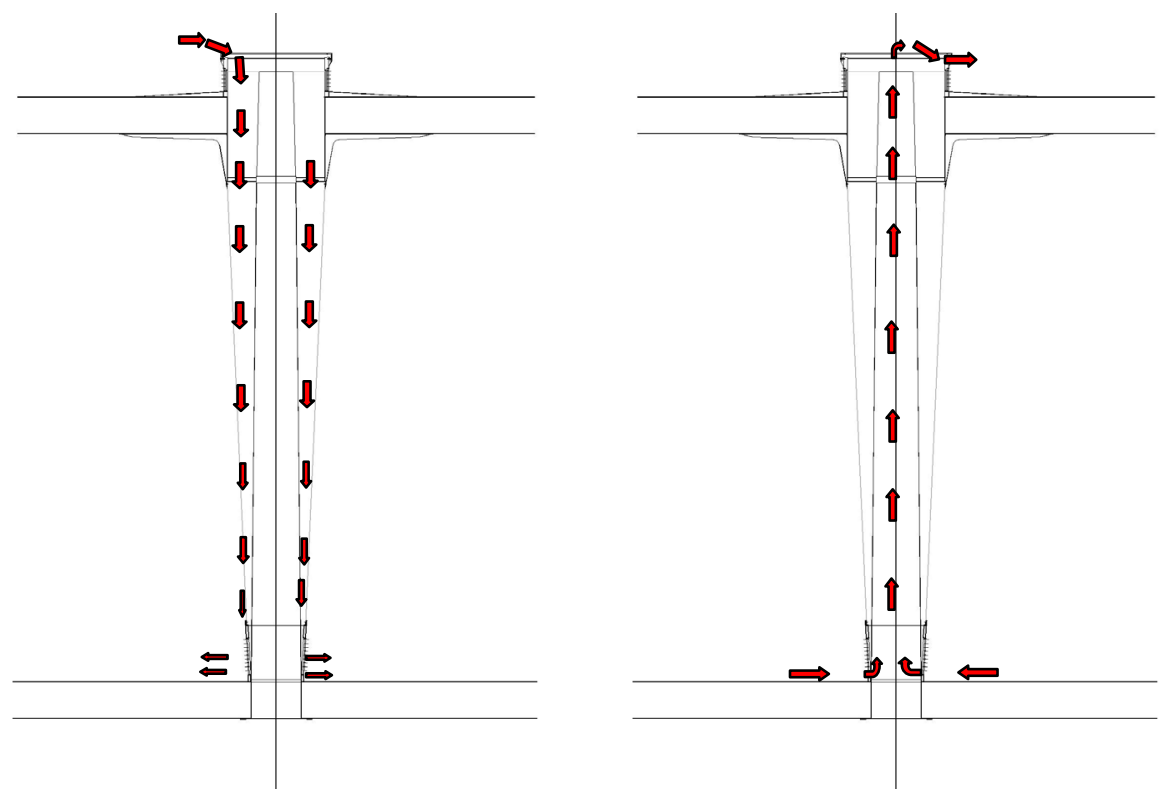

Fig. 9. Qualitative air circulation in an inlet and outlet VDLP

\subsection{The modular square form equipped by four Ventilated Double Light Pipes}

A certain number of VDLP can be installed in order to generate a modular architectural structure, by which more complex buildings of various geometrical forms may be obtained.
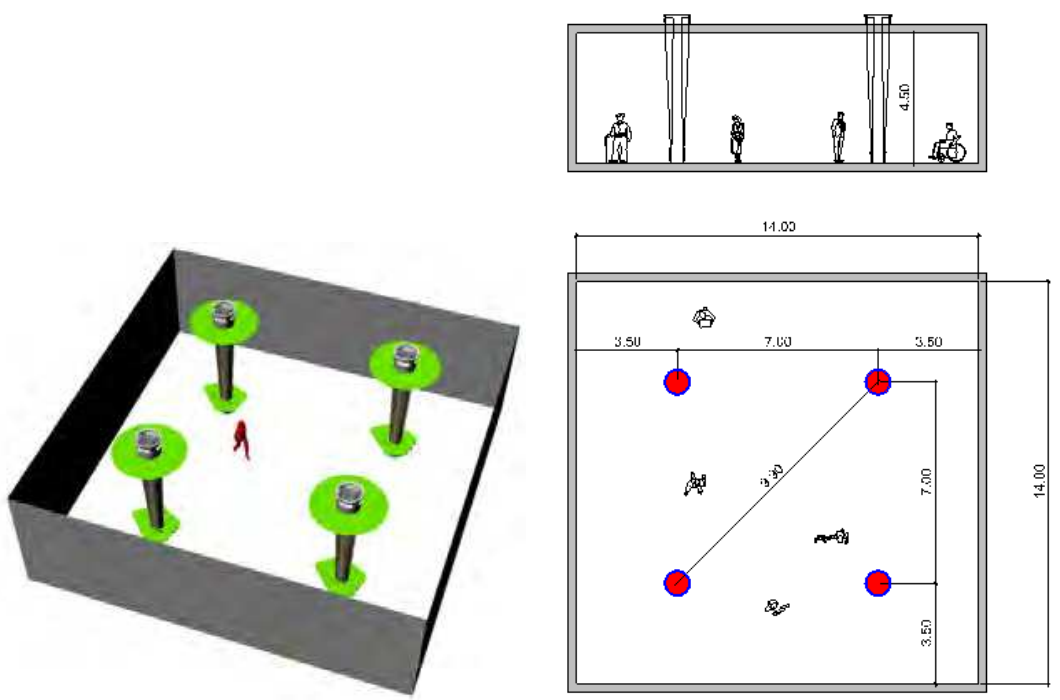

Fig. 10. Basic square modular form 
In Boccia et al (2011), the authors proposed a two - level square basic modular form with four VDLP and presented the results of a numerical simulation, regarding daylight and natural ventilation performances. Each level consists of a $14 \times 14 \mathrm{~m}^{2}$ plant area room, 4,5 m high, in which two inlet and two outlet devices are installed, with the intention of introducing daylight in both the intermediate and the final room. At the same time natural ventilation by the VDLP installed is achieved in the passage room. Figure 10 shows the square model equipped by four VDLP.

\subsection{Numerical analysis on the square modular form equipped with four VDLP}

An intense numerical analysis was carried out by the authors in steady state condition with the aim of determining the daylight illuminance and luminance distribution by the sw Radiance and Ecotect, while the sw package Fluent / Airpak was used in order to calculate the air velocities and temperatures in the room, besides the thermal comfort index PMV and PPD.

\subsubsection{Daylighting simulation}

In Figures 11 and 12, the numerical illuminance distribution on June the $21^{\text {st }}$ under Clear Sky, and on December the 21 $1^{\text {st }}$ under Overcast Sky respectively are shown, while in Figures 13 and 14 the internal luminance distribution in analogous conditions is shown. (Boccia et al. 2011)

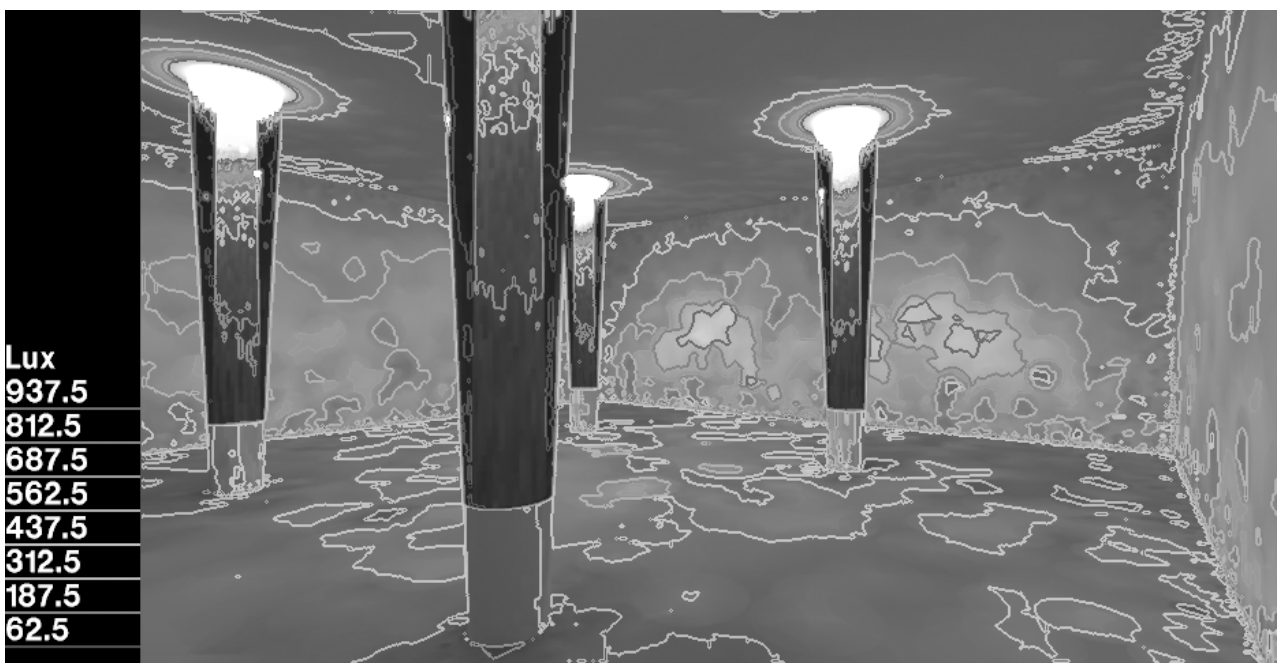

Fig. 11. Internal Illuminance distribution on June the 21 $1^{\text {st }}$ Clear Sky 


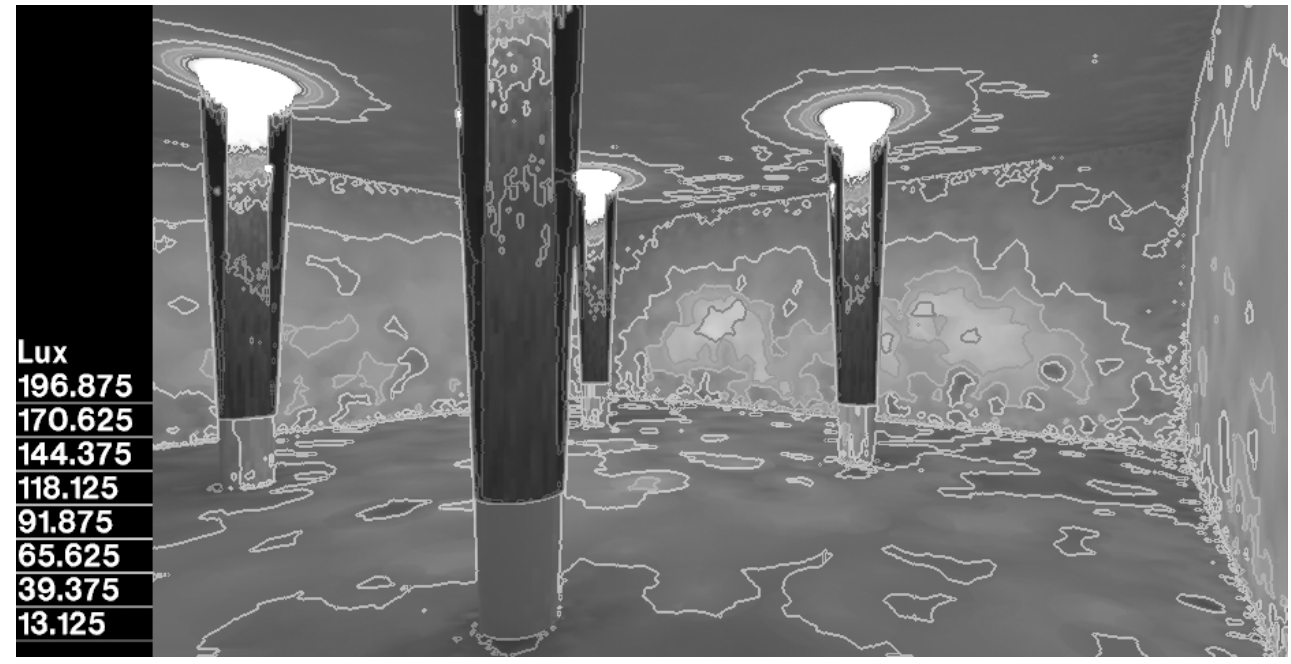

Fig. 12. Internal Illuminance distribution on December the $21^{\text {st }}$ - Overcast Sky

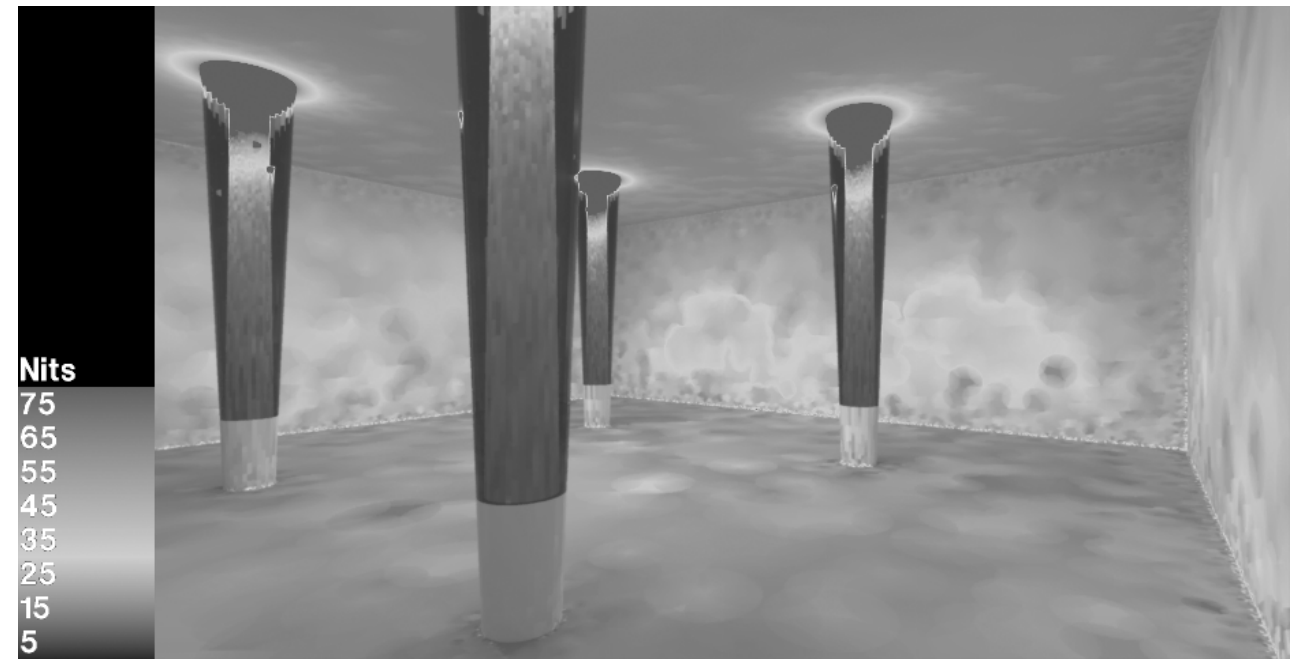

Fig. 13. Internal Luminance distribution on June the 21 1 st Clear Sky 


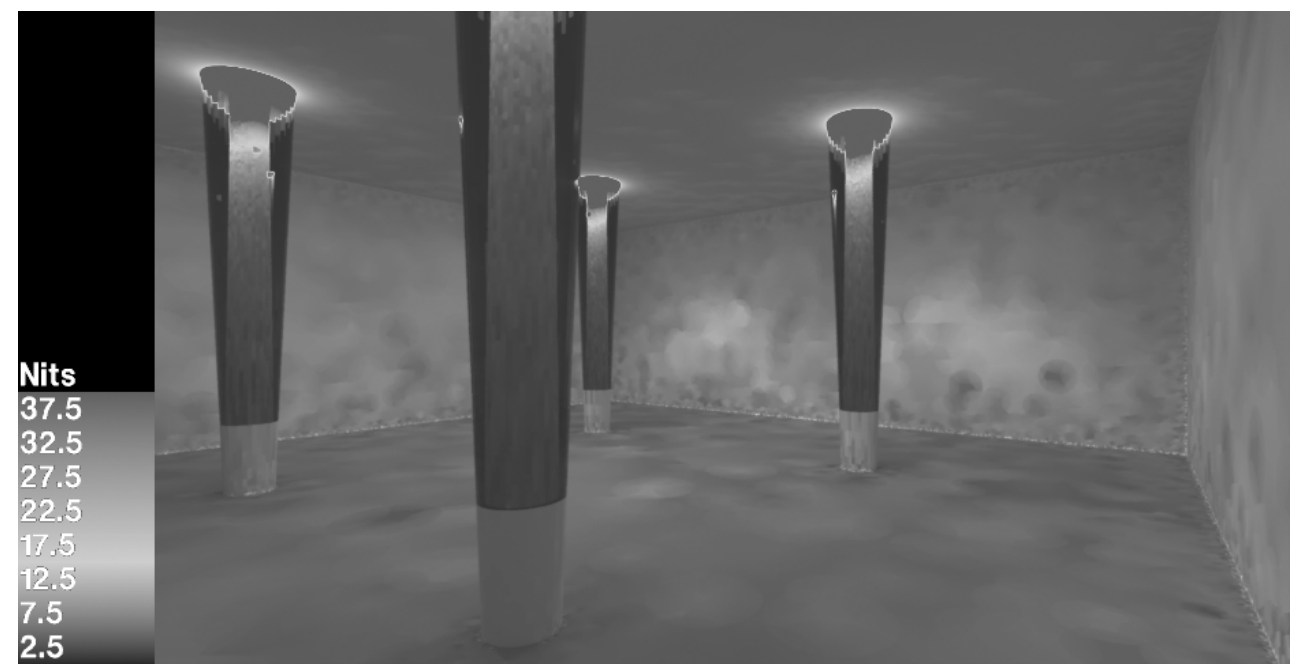

Fig. 14. Internal Luminance distribution on December the 21 $1^{\text {st }}$ - Overcast Sky

In summer condition, under CLEAR SKY, an average value of about 800 lux is obtained in the environment with maximum values of about 2700 lux in positions close to the tubes. The illuminance spatial trend is not symmetric due to the influence of the reflections coming from the devices and coming also particularly from the intense direct solar radiations. In winter conditions, under OVERCAST SKY an average value of 150 lux is obtained with maximum illuminance values of about 500 lux. A similar situation is obtained regarding the asymmetric distribution of illuminance with peak values close to the VDLP. The images regarding the luminance distribution in the room (Figures 13 and 14) show how the luminances are all over comfortably with some areas on the walls that appear particularly bright with_respect to the surrounding environment, as already evidenced in the picture of Figure 1. Only the upper portion of the tube is characterized by luminances so high that the risk of glare is present. In this case the adoption of a diffusing film applied on the internal surface of the transparent pipe is an appropriate antidote.

Starting from the results about daylighting the influence area of the VDLP has been determined in order to assure daylight comfort for the occupants. A centre distance between the VDLPs of $7 \mathrm{~m}$ has been chosen and on the basis of this geometric data the basic square modular form was designed.

\subsubsection{Winter simulation on thermal comfort indexes}

A further numerical analysis was carried out with the aim of determining the indoor thermo-hygrometric comfort index such as the air temperature and velocity, the PMV and PPD index, the mean age of air in winter and summer condition.

In winter condition the VDLP is not able to guarantee thermo-hygrometric comfort condition as confirmed by the air temperature data and the PMV and PPD comfort indexes (cfr. Figures 15 and 16). 

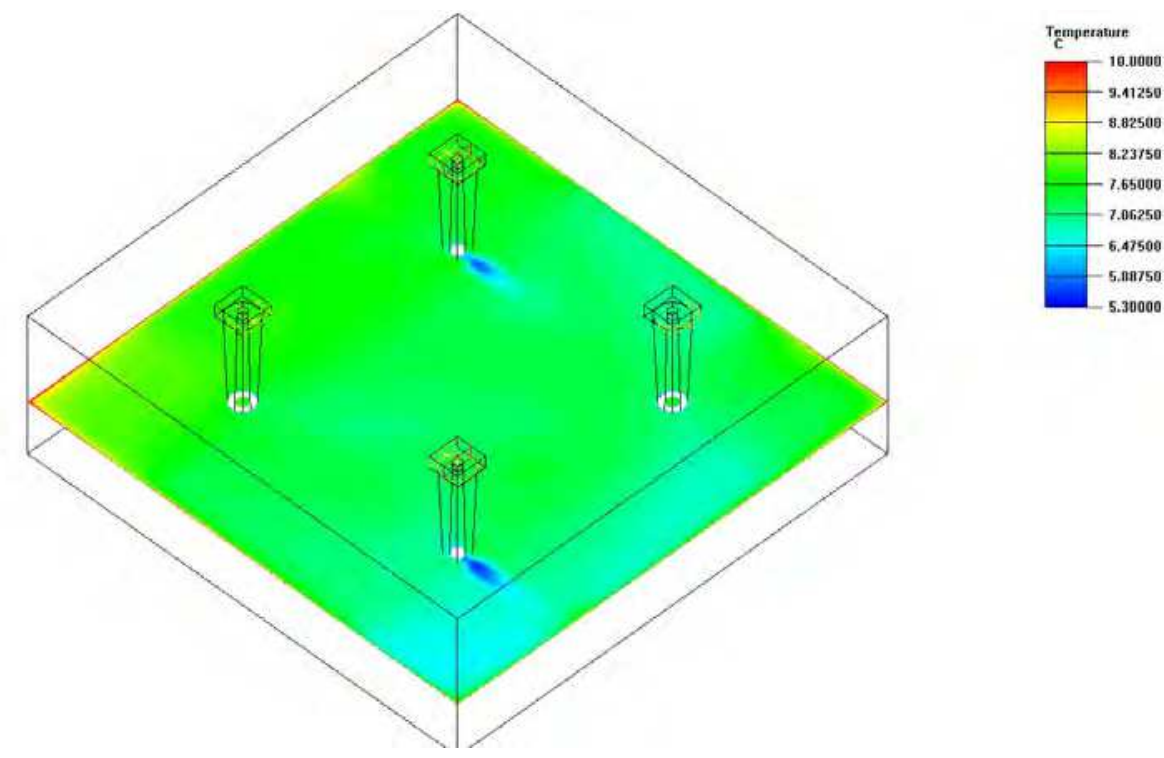

Fig. 15. Air temperature on a horizontal plan 1,7 $\mathrm{m}$ high on the floor
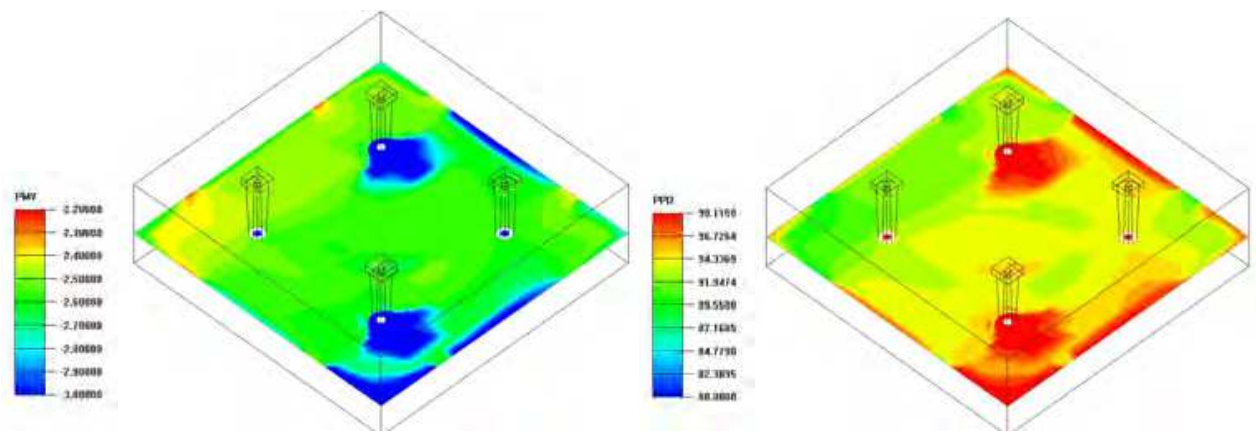

Fig. 16. PMV and PPD on a horizontal plane 1,7 $\mathrm{m}$ high above the floor

On the other hand, as underlined by graphs in Figures 14-17, the VDLP is able to guarantee a good natural air circulation. Figure 17 shows the air speed distribution on a horizontal plane $1,7 \mathrm{~m}$ above the floor in winter condition, with an external air temperature of $4{ }^{\circ} \mathrm{C}$, in a two - level underground building, and a ground temperature of $15^{\circ} \mathrm{C}$. In the passage room the boundary walls and the floor are considered isotherm with a temperature of $15^{\circ} \mathrm{C}$, while the ceiling is considered an adiabatic surface. The wind velocity corresponding to the inlet section of the collector is of $4 \mathrm{~m} / \mathrm{s}$. The wind direction is not considered because the device can vary its orientation in such a way that the inlet section is always normal to the wind direction.

Close to the inlet of the VDLPs, high values of air speed are observed (up to a maximum of about $0,5 \mathrm{~m} / \mathrm{s}$ ) while all over the environment the air velocity is less than $0,2 \mathrm{~m} / \mathrm{s}$ with quite a uniform spatial trend. In Figure 18 the vertical air velocity at the centre of the room, 
with the same boundary conditions is considered. It is evident that the vertical trend of air speed is quite uniform with very comfortable values, except for positions near the floor in which the suction action of the device causes high values of air speed. The vertical sections shown in Figures 19 and 20, corresponding to the inlet and outlet of the VDLPs, indicate that they are able to effect an efficient air change in the environment as confirmed by Figure 21 in which data about the mean age of air are reported. It is clear that the in flow of fresh air and the out flow of exhaust air is efficiently effected by the devices so that the mean age of air is satisfactory all over in the environment particularly near the inlet tubes. In fact the calculated inlet flow rate is about $720 \mathrm{~m}^{3} / \mathrm{h}$ which correspond to 0,8 air exchange in an hour.

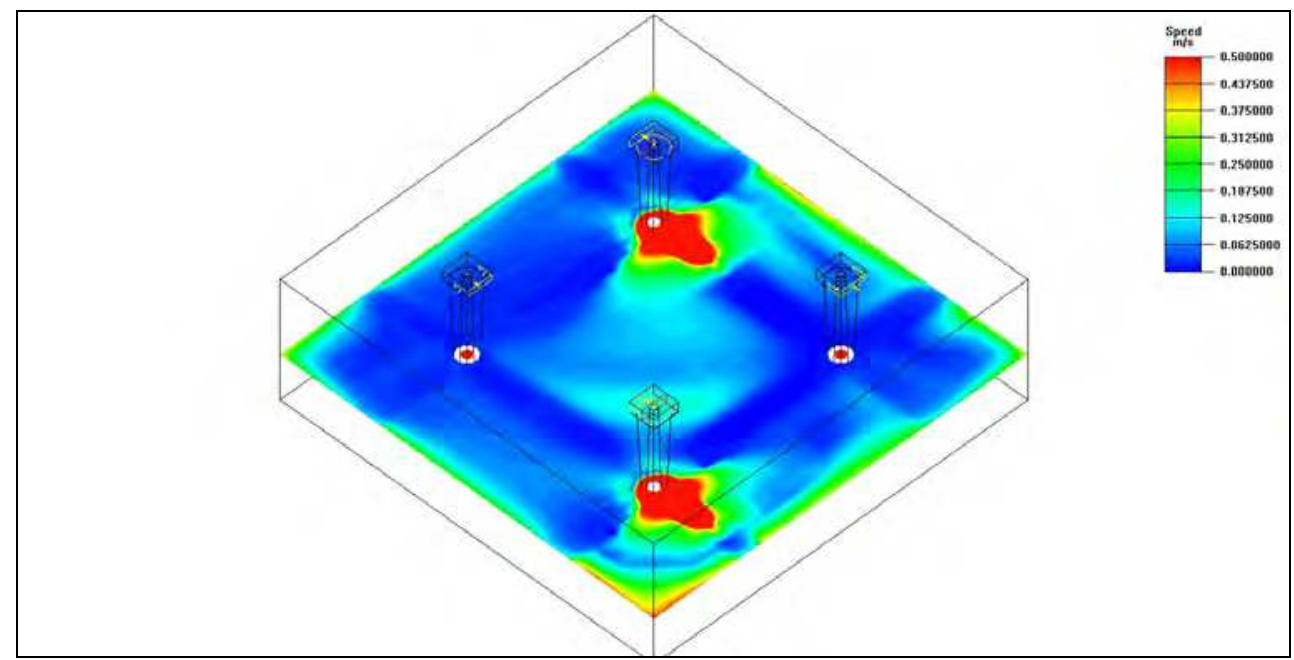

Fig. 17. Air velocity on a horizontal plane $1,7 \mathrm{~m}$ above the floor

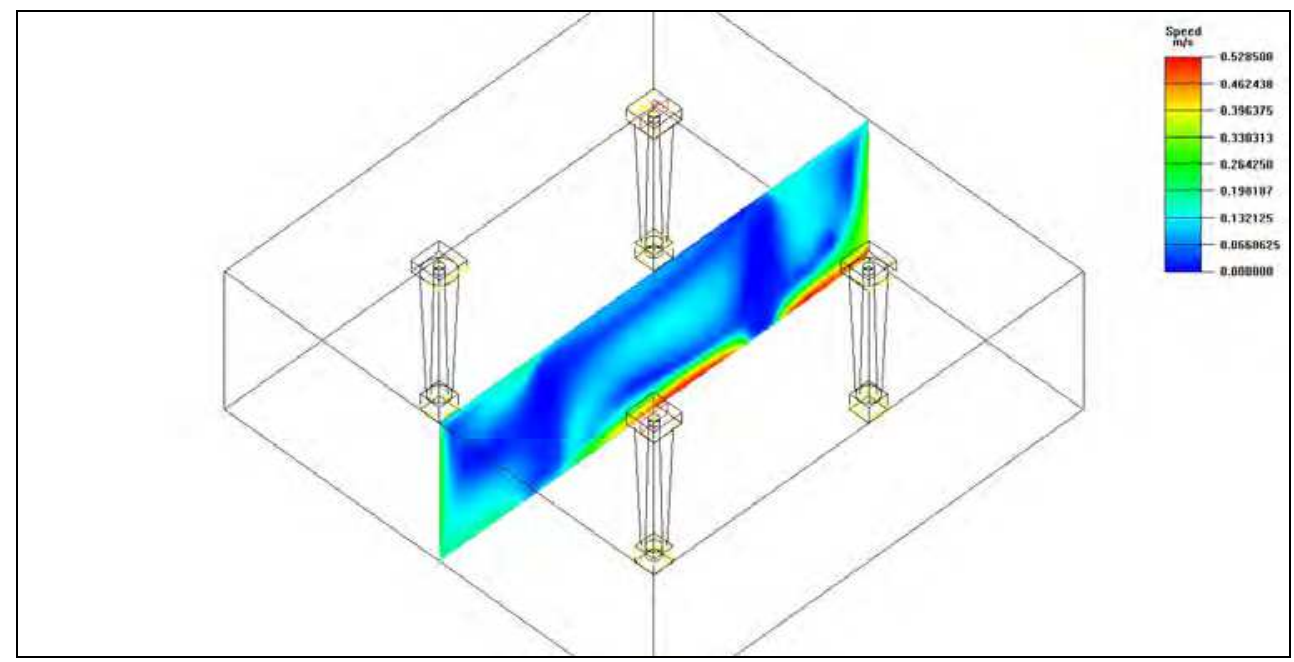

Fig. 18. Air velocity in the vertical plane at the centre of the room 


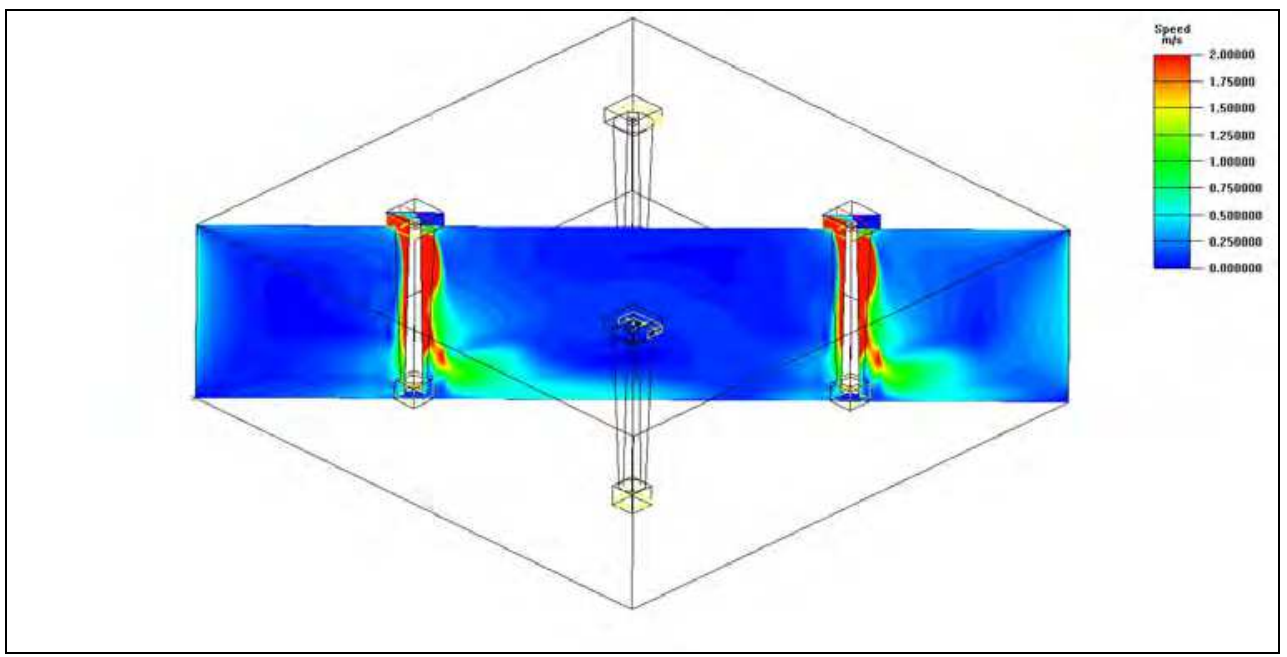

Fig. 19. Air velocity in a vertical section of the inlet tubes

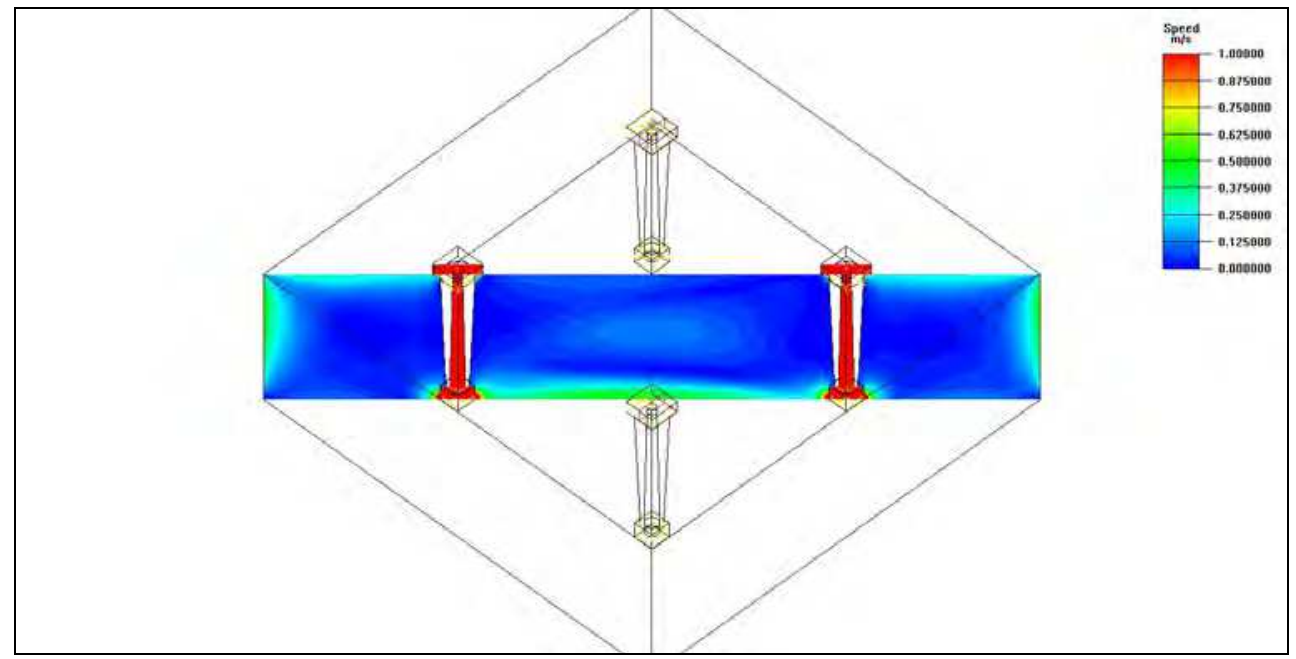

Fig. 20. Air velocity in the vertical section of the outlet tubes 


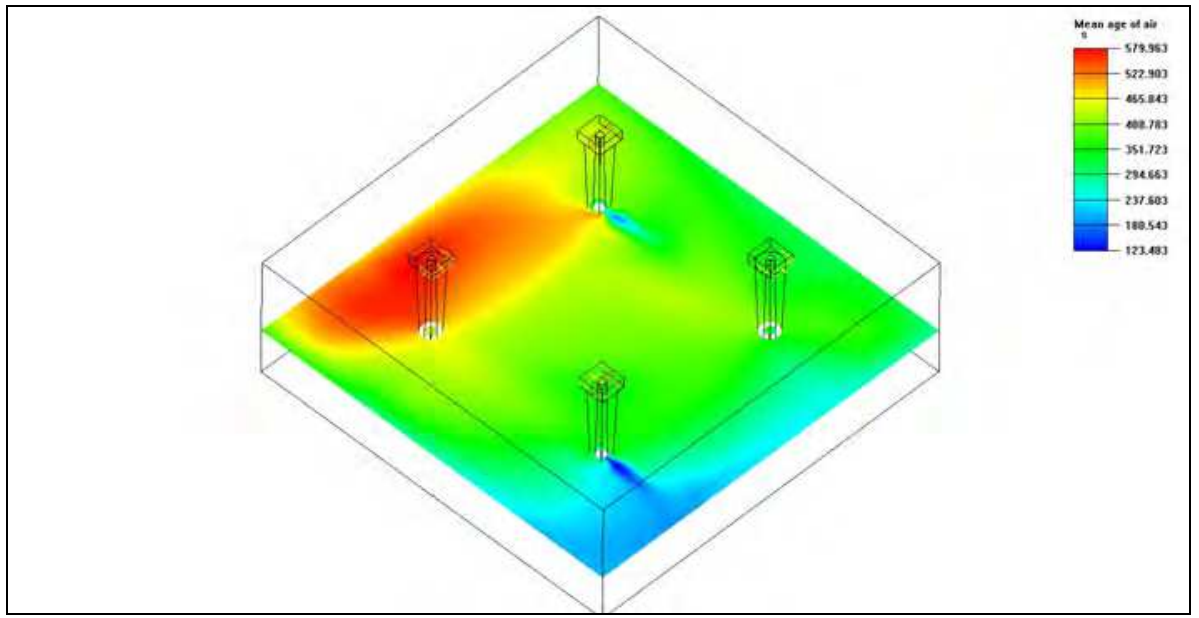

Fig. 21. Mean age of air on a horizontal plan 1,7 $\mathrm{m}$ high on the floor

\subsubsection{Summer simulation of thermal comfort indexes}

In summer condition, a better situation is observed in the thermal comfort indexes. The numerical simulation is carried out assuming an external air temperature of $30{ }^{\circ} \mathrm{C}$, with a relative humidity of $70 \%$ and a wind velocity of $4 \mathrm{~m} / \mathrm{s}$. The internal vertical walls and floor are considered isothermal with a surface temperature of $15{ }^{\circ} \mathrm{C}$, while the ceiling is considered adiabatic. In addition the external horizontal surface of the collector is superheated with respect to the air and its surface temperature is assumed equal to $36^{\circ} \mathrm{C}$ due to the effect of solar radiations. As evidenced in Figures 22 and 23, the indoor air temperature is included between about 25 and $27^{\circ} \mathrm{C}$, both on a horizontal plane $1,7 \mathrm{~m}$ high above the floor and in a vertical plane in the centre of the room.

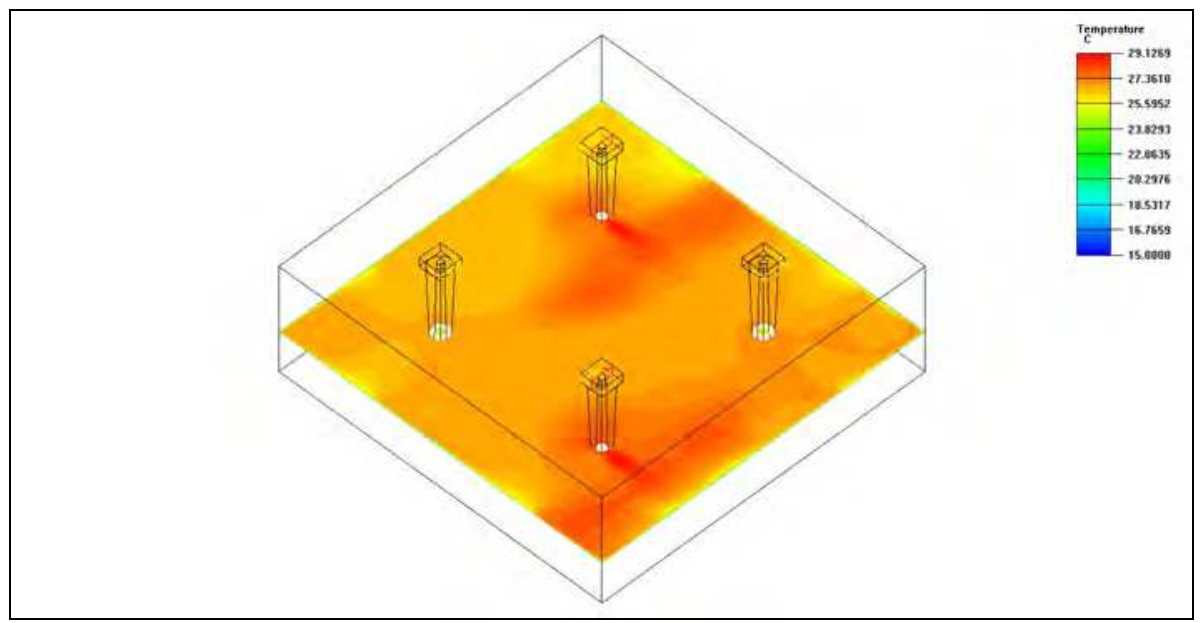

Fig. 22. Indoor air temperature in summer condition on a horizontal plane 1,7 $\mathrm{m}$ above the floor 


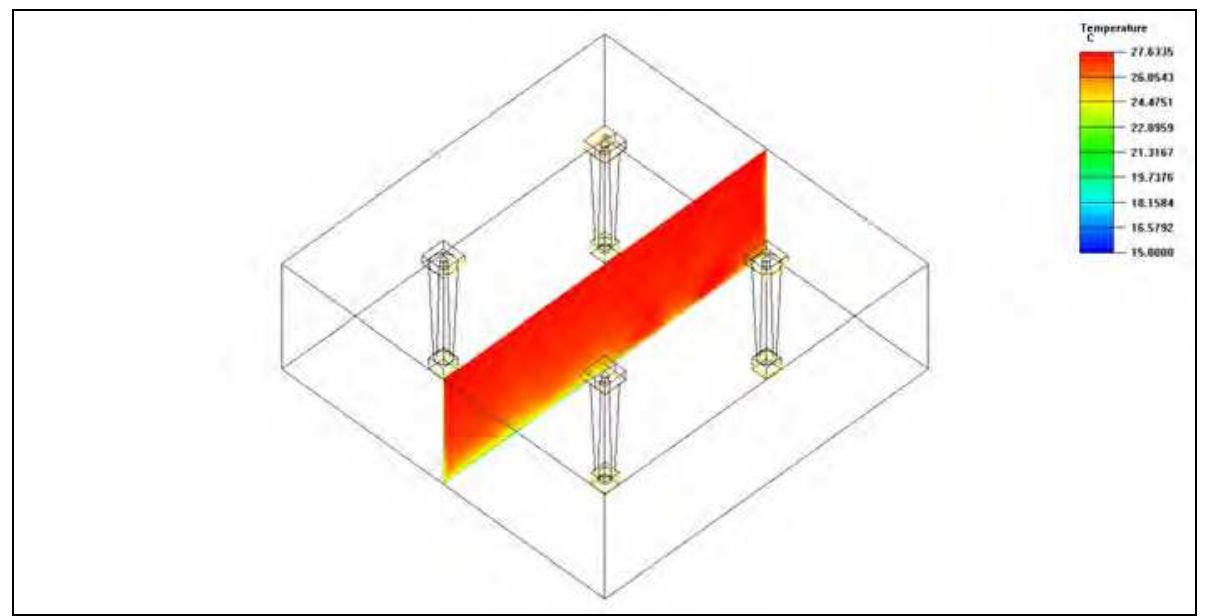

Fig. 23. Indoor air temperature in summer condition on a vertical plane in the centre of the room

Data about PMV and PPD indexes confirm that in the room a thermal comfort condition is obtained with the VDLPs in summer as shown by Figures 24 and 25, even though the internal relative humidity may not be satisfactory, ranging between 75 and $85 \%$ all over the environment. It is an expected result since air is only refreshed without any dehumidification action, so the R. H. is increasing due to the decreasing temperature. Hence we can deduce that the internal air must be de-humidified in order to ensure complete satisfactory thermo-hygrometric indexes.

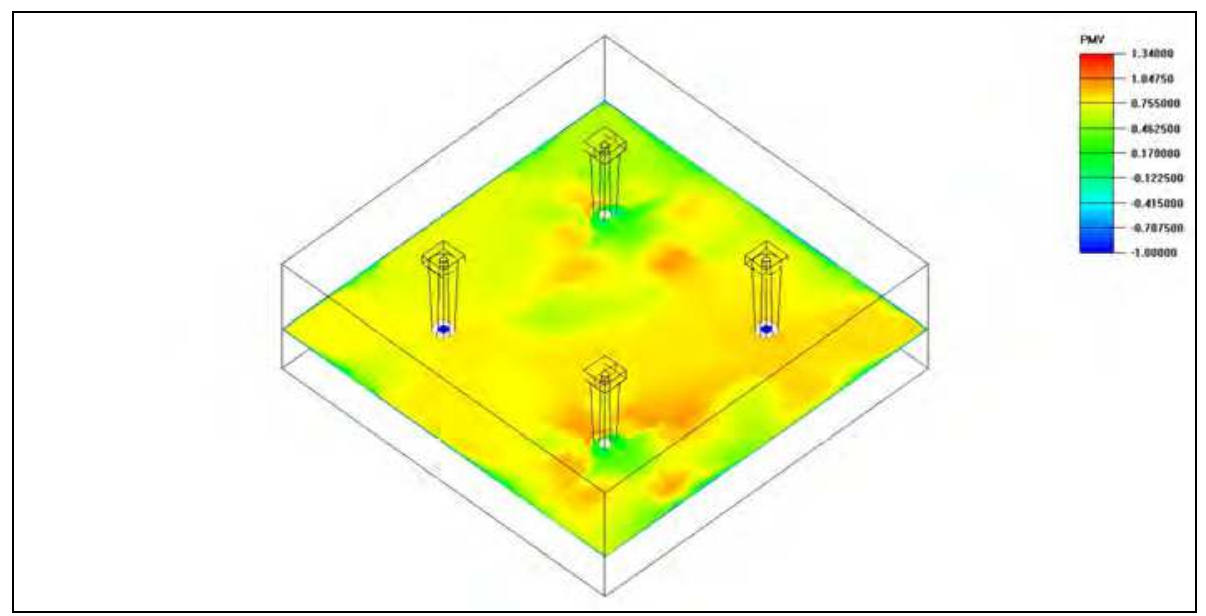

Fig. 24. PMV index on a horizontal plane $1,7 \mathrm{~m}$ above the floor 


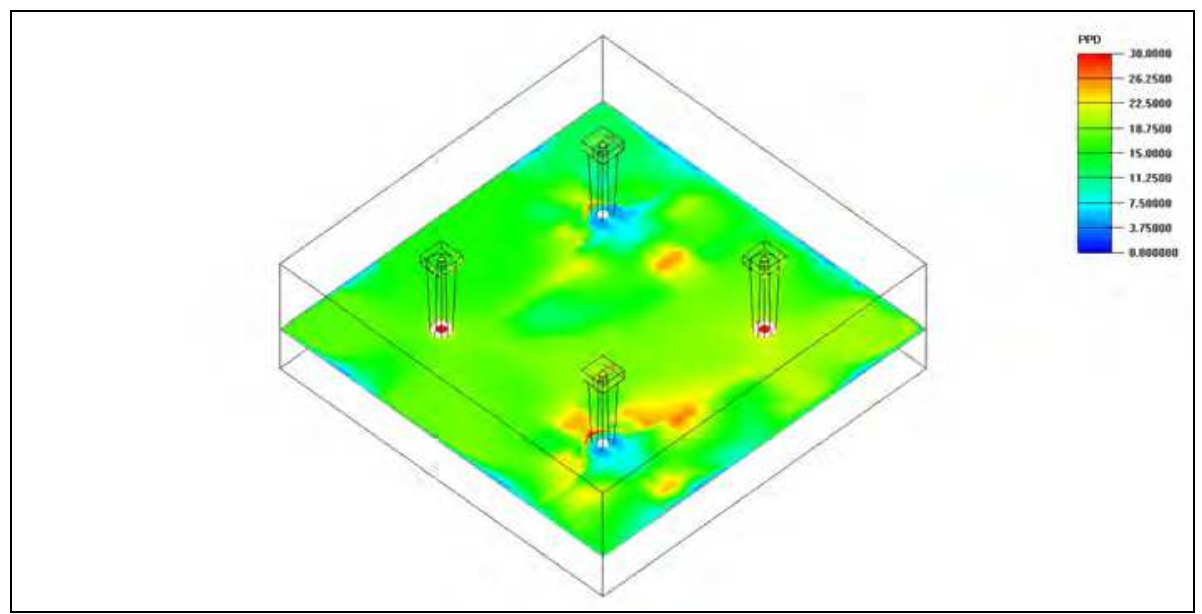

Fig. 25. PPD index on a horizontal plane 1,7 $\mathrm{m}$ above the floor

Regarding air velocity, we can say that the VDLPs seem to ensure good natural ventilation, since they are able to make available sufficient fresh air in the room and allow the necessary exchange of air for optimal hygienic condition. Figures 25-28 show the air speed spatial trend in the room on a horizontal plane and vertical plane, in the centre of the room and at the inlet and outlet devices. Being that in summer condition higher values of air velocity than in winter condition can be tolerated by the occupants of the environment, the air velocity is satisfactory both on a horizontal and vertical plane, and at the inlet, air flow-rate is able to sustain the necessary air exchange for hygienic comfort conditions. In fact the calculated inlet flow rate is about $540 \mathrm{~m}^{3} / \mathrm{h}$, which correspond to 0,6 air exchange in an hour.

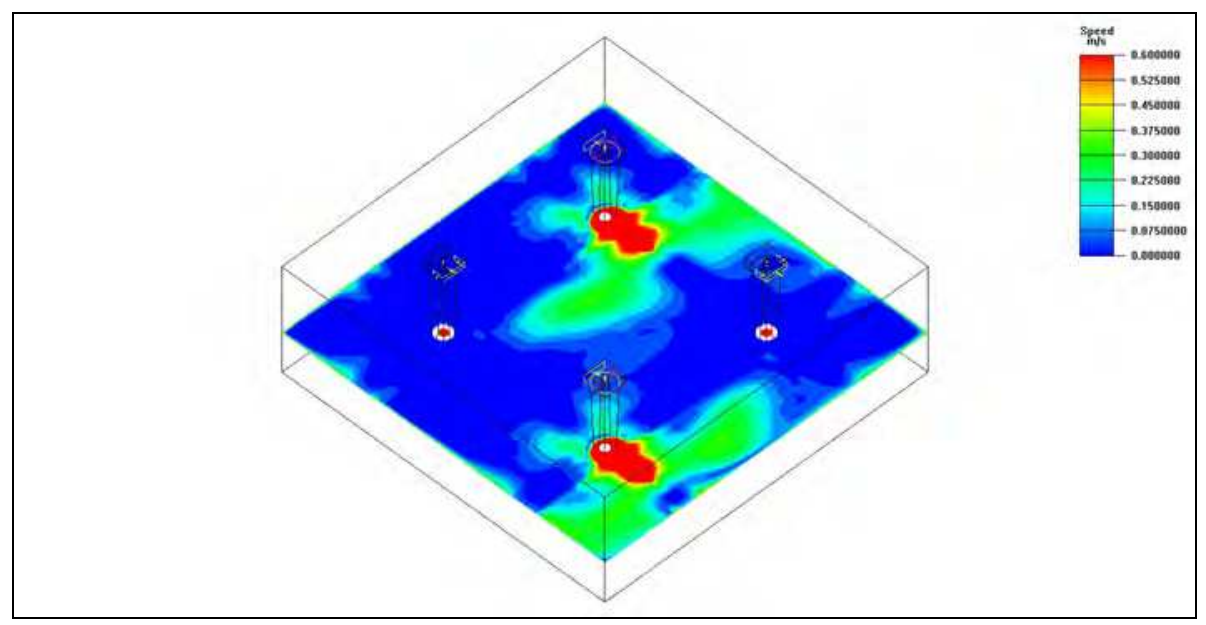

Fig. 26. Air velocity distribution on a horizontal plane $1,7 \mathrm{~m}$ above the floor 


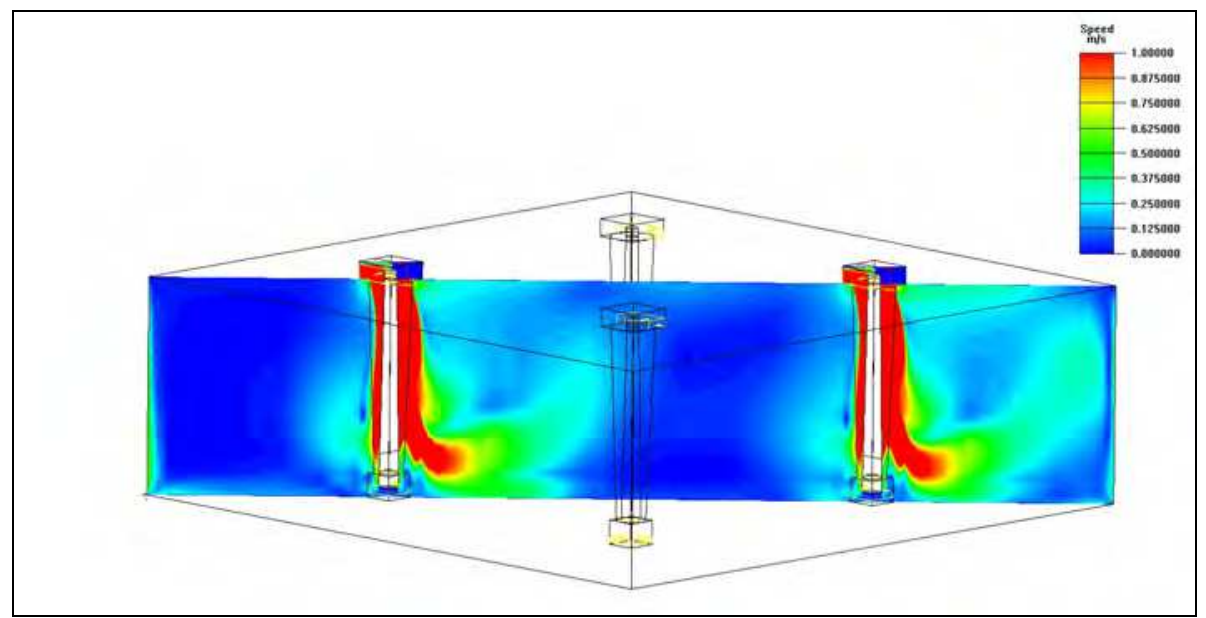

Fig. 27. Air velocity distribution on the vertical section at the inlet of VDLP

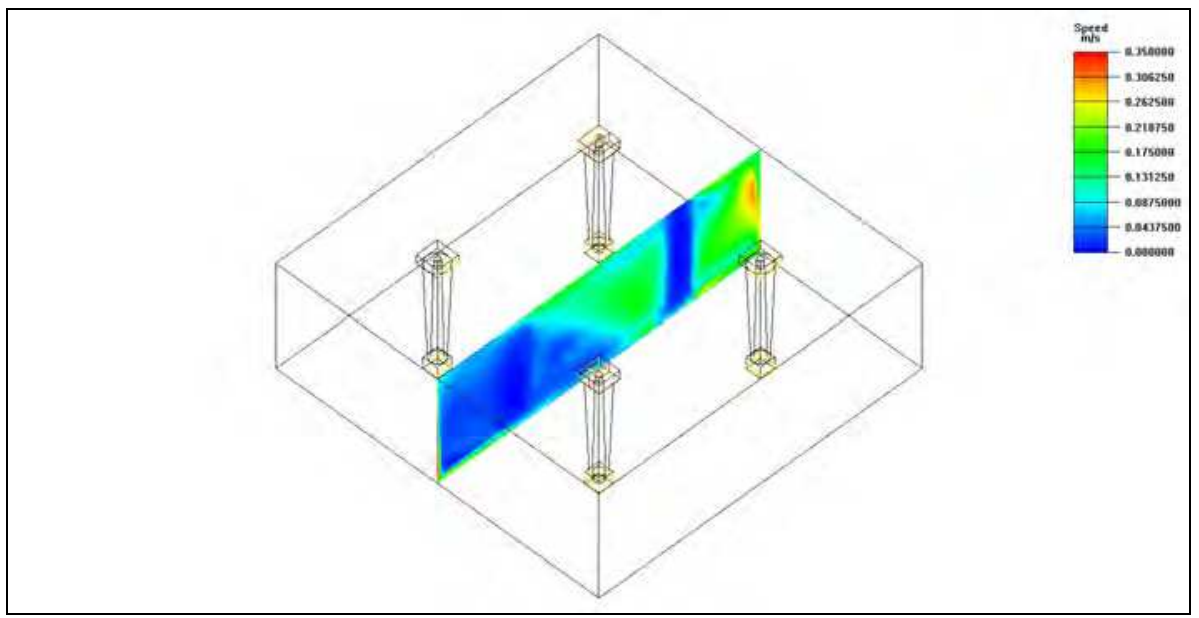

Fig. 28. Air velocity distribution on the vertical section at the centre of the room

\section{Conclusions}

In this work the authors show the results of an intense analysis carried out on some innovative devices for daylight transport and natural ventilation in underground areas of buildings or rooms without any direct connection with outside. Starting from the knowhow, achieved in many years of numerical and experimental activity regarding the traditional light pipes, they propose two innovative devices: the Double Light Pipe (DLP) and the Ventilated Double Light Pipe (VDLP). By the DLP the problem of the encumbrance of a traditional light pipe installed in the centre of a two - level underground building is resolved because it illuminates both the passage and the final room, while the VDLP, in addition, is able to effect the necessary air exchange in the passage room. 
The DLP was studied through a numerical and experimental analysis and its lighting performances are shown, while the VDLP was analysed by numerical methods by which its capacity to distribute fresh air in the passage room is investigated. Four VDLPs are composed in a basic modular form. The daylighting analysis allows the optimization of the centre distance between two adjacent devices to be set at $7 \mathrm{~m}$. The successive numerical analysis regarding the thermo-hygrometric comfort indexes confirm that the square shape of a module, although perfectible, at this moment, is preferable to more complex geometric shapes because it offers the advantage of adapting to various possible compositions of modules.

In particular, the data of the numerical thermo-hygrometric and fluid-dynamics analysis enable us to conclude that the VDLP is an efficient tool for natural ventilation both in summer and winter conditions. Besides, in summer, it assures a certain degree of thermal comfort with regards to the spatial temperature in the environment as confirmed by data from PMV and PPD indexes. However it cannot effect the dehumidification action necessary to ensure complete thermo-hygrometric comfort conditions in summer. In winter, it cannot guarantee thermal comfort for the occupants of the passage room, but it can be considered an efficient tool for natural ventilation.

\section{References}

Baroncini, C. ; Boccia, O. ; Chella, F. \& Zazzini, P. (2009). Double light pipe: experimental analysis on reduced scale models and comparison with numerical results, LUXEUROPA 2009, pp. 1041-1048, Istanbul, Turkey, September 07-11, 2009

Baroncini, C.; Chella, F. \& Zazzini, P. (2006). Experimental analysis of tubular light pipes performances: influence of the diffuser on inside distribution of light, 5th International Conference on Sustainable Energy Technologies SET 2006, pp. 219-224, Vicenza, Italy, August 30-September 01, 2006

Baroncini, C.; Boccia, O.; Chella, F. \& Zazzini, P. (2010). The Double Light Pipe, an innovative daylight technological device, Solar Energy, Vol. 84, No. 2 (February 2010), pp. 296-307, ISSN 0038-092X

Baroncini, C.; Chella, F. \& Zazzini, P. (2007). Numerical and experimental analysis on Double Light Pipe, a new system for daylight distribution in interior spaces, International Journal of Low Carbon Technologies, Vol. 3, No. 2 (April 2008), pp. 110125, ISSN 1748-1317

Boccia, O. ; Chella, F. \& Zazzini, P. (2011). Numerical analysis on daylight transmission and thermal comfort in the environments containing devices called "Double Light Pipes", World Renewable Energy Congress 2011, Linkoping, Sweden, May 08-13, 2011

Boccia, O.; Chella, F. \& Zazzini, P. (2011). Ventilated Illuminating Wall (VIW): Natural ventilation and daylight experimental analysis on a 1:1 prototype scale model, World Renewable Energy Congress 2011, Linkoping, Sweden, May 08-13, 2011

Boccia, O.; Chella, F. \& Zazzini, P. (2011). Ventilated Illuminating Wall (VIW): Natural ventilation numerical analysis and comparison with experimental results, World Renewable Energy Congress 2011 - Sweden, Linkoping, Sweden, May 08-13, 2011

Carter, D. J. (2002). The measured and predicted performances of passive solar light pipe systems, Light Research Technology, Vol. 34(1) , pp. 39-52. 
Chella, F.; Gentile, E. \& Zazzini, P. (2007). Natural light in new underground areas of a historical building: an example of application of double light pipes in preservation of the architectonic heritage, 6th International Conference on Sustainable Energy Technologies SET 2007, pp. 232-237, Santiago de Chile, Chile, September 5-7 2007

Chella, F.; Zazzini, P. \& Carta, G. (2006). Compared numerical and reduced scale experimental analysis on light pipes performances, 5th International Conference on Sustainable Energy Technologies SET 2006, pp. 263-268, Vicenza, Italy, August 30-September 01,2006

Jenkins, D. \& Muneer, T. (2004). Light-pipe prediction methods, Applied Energy, Vol. 79, pp. 77-86.

Jenkins, D., Zhang X. \& Muneer, T. (2004). Formulation of semi-empirical models for predicting the illuminance of light pipes, Energy Conversion \& Management, Vol. 46, pp. 2288-2300.

Jenkins,D. \& Muneer, T. (2003). Modelling light-pipe performances-a natural daylighting solution, Building and Environment, Vol. 38 pp. 965-972.

Zazzini, P. ; Chella, F.; Scarduzio, A. \& (2006). Numerical and experimental analysis of light pipes' performances: comparison of the obtained results, 23th Conference on Passive and Low Energy Architecture, Vol. 2, pp. 219-224, Geneva, Switzerland, September 6-8 2006

Zhang, X. \& Muneer, T. (2002). A design guide for performance assessment of solar light pipe, Light Research Technology, Vol. 34(2), pp. 149-169. 


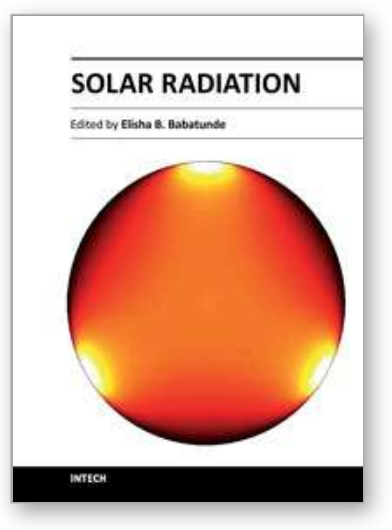

\author{
Solar Radiation \\ Edited by Prof. Elisha B. Babatunde
}

ISBN 978-953-51-0384-4

Hard cover, 484 pages

Publisher InTech

Published online 21, March, 2012

Published in print edition March, 2012

The book contains fundamentals of solar radiation, its ecological impacts, applications, especially in agriculture, architecture, thermal and electric energy. Chapters are written by numerous experienced scientists in the field from various parts of the world. Apart from chapter one which is the introductory chapter of the book, that gives a general topic insight of the book, there are 24 more chapters that cover various fields of solar radiation. These fields include: Measurements and Analysis of Solar Radiation, Agricultural Application / Bio-effect, Architectural Application, Electricity Generation Application and Thermal Energy Application. This book aims to provide a clear scientific insight on Solar Radiation to scientist and students.

\title{
How to reference
}

In order to correctly reference this scholarly work, feel free to copy and paste the following:

Oreste Boccia, Fabrizio Chella and Paolo Zazzini (2012). Innovative Devices for Daylighting and Natural Ventilation in Architecture, Solar Radiation, Prof. Elisha B. Babatunde (Ed.), ISBN: 978-953-51-0384-4, InTech, Available from: http://www.intechopen.com/books/solar-radiation/innovative-devices-for-daylighting-andnatural-ventilation-in-architecture

\section{INTECH}

open science | open minds

\section{InTech Europe}

University Campus STeP Ri Slavka Krautzeka 83/A 51000 Rijeka, Croatia Phone: +385 (51) 770447

Fax: +385 (51) 686166 www.intechopen.com

\section{InTech China}

Unit 405, Office Block, Hotel Equatorial Shanghai No.65, Yan An Road (West), Shanghai, 200040, China 中国上海市延安西路65号上海国际贵都大饭店办公楼 405 单元 Phone: +86-21-62489820

Fax: $+86-21-62489821$ 
(C) 2012 The Author(s). Licensee IntechOpen. This is an open access article distributed under the terms of the Creative Commons Attribution 3.0 License, which permits unrestricted use, distribution, and reproduction in any medium, provided the original work is properly cited. 